\title{
EDUCAÇÃO AMBIENTAL E CURRÍCULOS NÔMADES: CONEXÕES COM A FILOSOFIA PÓS- ESTRUTURALISTA
}

\author{
Helen Moura Pessoa ${ }^{1}$ \\ https://orcid.org/0000-0003-0106-3735
}

\section{RESUMO:}

Este trabalho busca articular algumas possibilidades curriculares para a educação ambiental, compreendendo os nomadismos que podem ocorrer nos espaçostempos escolares e comunitários. Na cartografia, produzida durante o doutorado em Educação, encontra composiçóes que podem promover aberturas nos bons encontros com os movimentos que atravessam a escola, a universidade e a comunidade, com as culturas locais e "conhecimentos outros". Aposta nos agenciamentos eco-comunitários para subverter o "monoculturalismo", por meio de conexões que transversalizam o multiculturalismo e suas articulações com a educação ambiental. Ao final, suscita a pensar em um currículo nômade como espaço de liberdade, sem barreiras e fronts, para potencializar o atravessamento de uma educação ambiental decolonial.

\section{EDUCACIÓN AMBIENTAL Y CURRÍCULOS NÓMADAS: CONEXIONES CON LA FILOSOFÍA POSTESTRUCTURALISTA}

\section{RESUMEN:}

Este trabajo pretende articular algunas posibilidades curriculares para la educación ambiental, entendiendo los nomadismos que pueden darse en los espacios tiempos escolares y comunitarios. En la cartografía, producida durante el doctorado en Educación, la investigación encuentra composiciones que pueden promover aperturas en buenos encuentros con los movimientos que atraviesan la escuela, la universidad y la comunidad, con las culturas locales y "otros saberes". A posta por las agencias eco-comunitarias para subvertir el "monoculturalismo", a través de conexiones que crucen el multiculturalismo y sus articulaciones con la educación ambiental. Al final, incita a pensar en un currículo nómada como un espacio de libertad, sin barreras ni frentes, para potenciar el traspaso de una educación ambiental decolonial.

\section{ENVIRONMENTAL EDUCATION AND NOMADIC CURRICULA: CONNECTIONS WITH POST-STRUCTURALIST PHILOSOPHY}

\section{ABSTRACT:}

This work seeks to articulate some curricular possibilities for environmental education, understanding the nomadisms that can occur in school and community spaces. In cartography, produced during the doctorate in Education, the research finds compositions that can promote openings in good encounters with movements that cross the school, the universi-
Palavras-chave:

Educação ambiental; Currículo; Decolonial; Filosofia.

Palabras clave: Educación ambiental; Currículo; Decolonial; Filosofía.

Keywords:

Environmental education; Curriculum; Decolonial; Philosophy.

1 Universidade Federal do Espírito Santo - Campus Alegre, Alegre, ES, Brasil. 
ty and the community, with local cultures and "other knowledge". Bet on eco-community agencies to subvert "monoculturalism", through connections that cross multiculturalism and its articulations with environmental education. In the end, the text prompts to think of a nomadic curriculum as a space of freedom, without barriers and fronts, to enhance the crossing of a decolonial environmental education.

\section{INTRODUÇÃO}

Enquanto escrevemos este texto, o mundo é atravessado por vários acontecimentos - todos imbricados - como a exploração socioambiental, a emergência climática e a pandemia pelo novo coronavirus. ${ }^{1}$ Crises que foram engendradas ao longo do tempo por máquinas colonizadoras, que buscam subtrair e suprimir os desejos, utilizando suas engrenagens midiáticas de controle.

Não queremos com isso tentar justificar ou negar a gravidade de tais crises, pelo contrário. Trata-se de uma denúncia: a exploração sem limites da rede socioambiental, o que inclui humanos, animais e natureza imbricados, trouxe-nos consequências desastrosas, que foram amplamente divulgadas por vários cientistas e ativistas ao longo de vários anos (Cheng et al., 2007; Tajra, 2020). A negação de todas essas evidências é que faz parte de um projeto muito maior de captura, controle dos corpos e ampliação do poder dos governos sobre essa rede.

Em meio a esse amontoado de crises, revoluçóes podem surgir a todo momento, em linhas de fuga, em um plano muito mais molecular, como Guattari (1987) ressalta em seus estudos. Uma revolução que vai na direção das mutaçôes do desejo, capaz de pôr em questão toda uma ordem estabelecida, que questiona as relaçôes de exploração e controle, de docilização dos corpos. ${ }^{2}$ É o que buscamos produzir nesta pesquisa, ao relembrar experiências de movimentos em conexão com as escolas-comunidades durante a realização do doutorado em Educação, onde imaginamospensamos que os fluxos rebeldes de desejo e suas constantes mutações podem ensejar liberdade de aprendizagem, criando, coletivamente, mundos possíveis por meio de currículos dinâmicos e nômades.

Aqui, apostamos nos nomadismos curriculares como possibilidade de visibilizar dimensóes educacionais menores ${ }^{3}$ e potentes que acontecem nos espaçostempos ${ }^{4}$ escolares e comunitários.

A educação ambiental pode se situar em um território instável e fluido, se considerarmos que o conhecimento se produz nas inúmeras experiências que ocorrem nos espaçostempos da vida. Mesmo cerceada pelos clichês (sustentabilidade, conscientização e desenvolvimento sustentável) e tentativas de redução (ao relacionar ao lixo/ coleta seletiva e conservação/preservação da natureza), sempre há possibilidade de educações ambientais "outras", criadas e inventadas por aqueles e aquelas que ousam subverter a lógica consumista/desenvolvimentista.

Neste texto, tentamos articular algumas possibilidades curriculares praticadas e observadas durante o doutorado em Educação da autora, que visualizem essas educaçôes ambientais menores, que acontecem nos cotidianos escolares-comunitários. Como as composições que ocorrem quando os movimentos coletivos atravessam a Educação Básica, com as culturas locais e "conhecimentos outros”, que muitas vezes podem subverter o que associamos ao "monoculturalismo", promovendo conexóes e agenciamentos que transversalizam o multiculturalismo. Nos suscitando a pensar o currículo nômade como espaço de liberdade, sem barreiras e fronts.

\section{EDUCAÇÃO AMBIENTAL E DECOLONIALIDADE}

Deleuze e Guattari, ao realizarem uma recriação - criar a partir do criado - de conceitos, promovem provocaçôes que levam a um "outro" pensar por meio de agenciamentos. Esses agenciamentos, por sua vez, promovem outros mais, pois, para os autores, o conhecimento é assim... rizomático, transversal e nômade.

Como os conceitos de molar e molecular... enquanto, na Química, molar se refere a um número fixo 
de entidades $\left(6,02 \times 10^{23}\right)$; molecular remete a moléculas, que não seguem nenhum padrão e se ligam de múltiplas formas. Essa relação é semelhante aos conceitos de Deleuze \& Guattari (2011a, 2011b), que consideram que molar se relaciona com os modelos dominantes, linhas duras e sedentárias; já molecular se refere às multiplicidades, linhas flexíveis, nômades e revolucionárias.

Entretanto, longe de assumirem um caráter dicotômico nesses conceitos (esse ou aquele), os autores articulam que molares e moleculares coexistem (esse e aquele). Ou seja, apesar das forças ativas, para Deleuze e Guattari, serem moleculares, coexistem ali as forças molares (reativas) prontas para cristalizar. Onde forças molares atuam, podem surgir fugas.

Articulando esses conceitos para a educação ambiental, observamos que muitas vezes a educação ambiental pode se articular de forma molar institucionalizada, como também em linhas moleculares nas escolas-universidades-comunidades. Dialogando com Guattari (1987), podemos talvez imaginarpensar que as linhas moleculares na educação ambiental podem seguir por aberturas rizomáticas com as comunidades e culturas locais, o que relacionamos com os agenciamentos ecocoletivos promovidos pela máquina desejanteambiental.

Entendemos que, mesmo sem a intenção institucional, a educação ambiental pode se articular, talvez como linhas de fuga, engendrando fluxos de reexistências nos espaços-tempos. Portanto, para além das tentativas de aprisioná-la a conceitos engendrados a serviço da economia, como a "educação para o desenvolvimento sustentável” (EDS), ou ao clichê da sustentabilidade, a educação ambiental pode reexistir por agenciamentos ecocoletivos, como também aposta Gonzalez-Gaudiano (2005, p. 236):

Naquilo para que realmente pode contribuir significativamente a educação é no desvendar desta tela de fundo, fornecendo capacidades para desconstruir as tendências propensas à ocultação ou à distorção da ordem social que está subjacente no discurso da sustentabilidade do desenvolvimento.

Ao buscar autoras e autores no Brasil que também dialogam com uma educação ambiental para além da instituição, encontramos educaçôes ambientais outras, que investigam engendramentos nas culturas e movimentos sociais locais. Educaçóes ambientais que se afastam das normas descritas pelas organizaçóes normativas mundiais - como a Organização das Nações Unidas para a Educação, a Ciência e a Cultura (Unesco) que, segundo Gonzalez-Gaudiano (2005), desconhece a realidade dos países em desenvolvimento e a verdadeira "parcela de culpa" dos países desenvolvidos, quanto à exploração de recursos naturais e humanos dos países em desenvolvimento para aplacar as satisfaçóes consumistas.

Nas obras organizadas por Tristão (2018) e por Henning, Mutz \& Vieira (2018), podemos fazer uma jornada entre pesquisas que articulam educações ambientais moleculares em conexão com as comunidades, escolas, artes e resistências.

Tristão (2018) organiza a obra $A$ educação ambiental e o pensamento pós-colonial: narrativas de pesquisas com trabalhos produzidos no potente grupo de pesquisa em educação ambiental, Nipeea/Ufes, ${ }^{5} \mathrm{com}$ contribuição do Gpea/UFMT, ${ }^{6}$ em conexão com culturas locais. A organizadora destaca: "Em nosso entendimento, essas novas abordagens no campo da pesquisa em educação ambiental denotam uma mudança epistemológica em direção a modos mais expansivos e sobrepostos de pensar o meio ambiente na educação com espaços e lugares sociais e culturais” (Tristão, 2018, p. 13).

Nessa mesma perspectiva, da qual buscamos nos aproximar - que concebe a educação ambiental como uma "pedagogia da incerteza" (Tristão, 2009) ou, como diria Gonzalez-Gaudiano (2005), como uma “pedagogia das margens”, Henning, Mutz \& Vieira (2018, p. 16) organizam a obra Educaçóes ambientais possiveis: ecos de Michel Foucault para pensar o presente. Segundo as organizadoras:

[...] trata-se de pensar de novo e vislumbrar experiências possíveis que nos coloquem no jogo da vida, pensando as relaçốes que estabelecemos com o meio ambiente e o atual cenário político educacional que estamos imbricados. É com a utilização de ferramentas foucaultianas e seu abandono, quando é preciso pensar por si mesmo, que este livro deseja munir seus leitores com apostas possíveis para a Educação Ambiental. 
Pensar nas possibilidades e criar mundos possiveis em meio aos engendramentos das máquinas colonizadoras é como relacionamos os nomadismos na educação ambiental. Assim, outro conceito dialogado com os intercessores é o de máquinas.

Segundo Deleuze \& Guattari (2011a), em uma sociedade capitalista e/ou socialista, a estrutura social pode ser entendida como máquina, assim como Maturana (2001, p. 174) afirma: “[...] sistemas vivos são máquinas”, em que os órgãos no corpo humano trabalham maquinamente para manter o ser vivo. Deleuze \& Guattari (2011a) esclarecem que as máquinas capitalísticas operam de forma a sustentar o corpo social. Segundo os autores, toda máquina é “máquina de máquinas”, pois elas sempre estão em um processo de produção, promovendo desterritorializações, reterritorializações, descodificações.

Deleuze \& Guattari (2011a) também tecem “diferenças” entre as máquinas molares e as moleculares, apesar do limiar tênue entre seus processos de produção. São molares as máquinas dominantes. Dentre elas, os autores exemplificam citando as máquinas sociais, técnicas ou orgânicas; já as máquinas moleculares são as desejantes.

As máquinas molares possuem engrenagens de dominação e exploração a fim de obter seus "produtos finais”. A história da colonização portuguesa no Brasil talvez possa estabelecer relação com essa atuação maquinica nas instituiçôes, em que podem promover territorializações do uno, codificando fluxos colonizadores de poder, de saber e de ser. De acordo com Guattari \& Rolnik (1996, p. 38), "É, portanto, num só movimento que nascem os indivíduos e morrem os potenciais de singularização”.

Talvez a produção de subjetividades promovida pela máquina molar colonizadora ainda permaneça e atue com seus mecanismos na sociedade, uma vez que essa máquina molar pode se atualizar e, ao incorporar as engrenagens da máquina capitalística, o que neste texto atribuímos à colonialidade, ${ }^{7}$ pode manter suas formas de controle em meio às novas tecnologias e/ou a outras formas. Isso porque, segundo os autores: “ $\mathrm{O}$ capitalismo instaura ou restaura todos os tipos de territorialidades residuais e factícias, imaginárias ou simbólicas, sobre as quais ele tenta, bem ou mal, recodificar, reter as pessoas derivadas das quantidades abstratas" (Deleuze \& Guattari, 2011a, p. 53).

Além disso, Guattari (1987, p. 205) ressalta que: “O capitalismo se apodera dos seres humanos por dentro. Sua alienação pelas imagens e ideias é apenas um dos aspectos de um sistema geral de servomecanismo de seus meios fundamentais de semiotização, tanto individuais quanto coletivos".

Sobre o servomecanismo, que pode ser engendrado pelo capitalismo na dominação subjetiva, Guattari (1987, p. 206) complementa: "É por intermédio do servomecanismo maquínico que ele se instala no coração dos indivíduos”. Em outra obra, ao compor com Deleuze, afirma que, nessa maquinação, "[...] o real não é impossível, ele é cada vez mais artificial” (Deleuze \& Guattari, 2011a, p. 53), o que nos suscita a problematizar: como se movem os fluxos de reexistências na trama da colonização, onde não somente os corpos são colonizados, mas também os pensamentos?

Nas tentativas de produzir pistas para essa questão, aproximamo-nos novamente de Deleuze \& Guattari (2011a), que desenvolvem o conceito das máquinas moleculares. Nessas máquinas que, para os autores, são flexíveis e formativas, até suas falhas são funcionais. Elas operam por ligações não localizáveis e por localizaçôes dispersas. São máquinas desejantes por terem como mola propulsora os desejos, funcionam desarranjando-se constantemente e sua produção é multiplicidade pura. Entretanto, sempre há possibilidade de cristalizaçôes, como um fascismo "microscópico" (microfascismos) que "[...] se instaura no seio das máquinas desejantes” (Guattari, 1987, p. 20).

Nessa perspectiva, imaginamospensamos em uma educação ambiental decolonial, que pode operar como uma máquina desejanteambiental, produzindo no e do comum. Enquanto a máquina da colonialidade pode promover processos de "individuação", que Guattari conceitua como a "alienação do desejo" (Guattari \& Rolnik, 1996), a máquina desejanteambiental poderia engendrar processos de singularização, que são “[...] processos disruptores no campo da produção do desejo [e] movimentos de protesto do inconsciente” contra a subjetividade capitalística (Guattari \& Rolnik, 1996, p. 45). 
Nesse sentido, poderíamos imaginarpensar a potencialidade dos engendramentos da máquina desejanteambiental em reterritorializar o que a máquina da colonialidade desterritorializou... a relação com a terra, com as culturas, os afetos... o desejo de compor os coletivos, os desejos eco-comunitários. Assim, poderíamos problematizar: será que os movimentos de reexistências ao promoverem conexóes com as comunidades e escolas buscando novas potências de agir, sentir, imaginar e pensar, podem potencializar o atravessamento de uma educação ambiental decolonial por meio dos engendramentos da máquina desejanteambiental?

Em meio a uma formação monocultural, talvez os fluxos descodificados pela máquina desejanteambiental promovam fissuras na composição de currículos, culturas e vivências. Cartografar esses fluxos de composiçóes curriculares pode nos fornecer pistas para pensar as possibilidades de atravessamentos da educação ambiental nos currículos escolares.

Guimarães \& Sampaio (2014) fazem outro movimento, mas ressaltam a potência na articulação das pesquisas em educação ambiental com os Estudos Culturais. Ao dialogarem com Lawrence Grossberg e vários outros pesquisadores em Estudos Culturais, ressaltam que "um dos efeitos dos Estudos Culturais na Educação Ambiental é sua abertura à multiplicidade, quando se trata de contar histórias sobre as relaçóes socioambientais, sobre os nossos modos de viver” (p. 132). Para o autor e a autora, essa articulação promove fissuras no dispositivo da sustentabilidade, o que relacionamos com os engendramentos da máquina desejanteambiental ao descodificar os fluxos colonizadores nos currículos.

Nessa mesma concepção, podemos situar os estudos realizados no núcleo de pesquisa Nipeea/Ufes, no qual buscam uma permanente correlação entre o lugar, as culturas e as produções narrativas locais nas produçóes acadêmicas. Os estudos de Tristão (2012) compreendem a educação ambiental em uma concepção que se aproxima da pós-colonial, multicultural, na busca por alternativas aos processos homogêneos de desenvolvimento econômico e cultural que a globalização impôs e generalizou como únicas possibilidades. Segundo a autora:

O monoculturalismo é contrário à ideia ecológica de mundo, porque é sempre uma ideia de força, de uma cultura de guerra em sentido metafórico, o que anula a diversidade de pensamentos e de açốes. A valorização das culturas pode ser um meio para construir um futuro sustentável (Tristão, 2012, p. 219).

Em nossa pesquisa, acreditamos que podemos observar os engendramentos da máquina desejanteambiental nos estudos de Tristão, ao problematizar a valorização das culturas como forma de favorecer a sustentabilidade, o que também pode nos fornecer pistas para essa cartografia. Neste texto, também compreendemos que os movimentos de reexistências, ao promoverem as culturas nas comunidades e escolas, podem criar possibilidades para a educação ambiental em uma perspectiva decolonial em meio a colonialidade do poder e do saber.

Para Quijano (2005) a globalização pode ser compreendida como a culminação de um processo que começou com a constituição da América e do capitalismo colonial/moderno e eurocentrado como um novo padrão de poder mundial. Nesse pensamento, o autor desenvolve sobre a colonialidade do poder, processo ainda em curso, que provou ser mais duradouro e estável que o colonialismo.

Bernadino-Costa, Maldonado-Torres \& Grosfoguel (2019, p. 9) também adensam essa problematização ao ressaltar que "a colonização no âmbito do saber é produto de um longo processo de colonialidade que continuou reproduzindo lógicas econômicas, políticas, cognitivas, da existência, da relação com a natureza, etc. que foram forjadas no período colonial”.

Nesse contexto, Tristão (2016, p. 35) discorre sobre a importância de compreender como a colonização, seguida da colonialidade, produziu e produz “[...] marcas históricas de assimetrias, de exploração da natureza, de subjugação dos povos colonizados, de dominação das culturas com a imposição do cristianismo e pela imposição civilizadora, desenvolvimentista e intervencionista”, para que possamos nos contextualizar, auxiliar na desconstrução dos discursos colonizadores e produzir nossas próprias narrativas.

Esses engendramentos decolonizadores também podem ser observados no artigo de Tristão \& Vieiras (2017), no qual observamos a importância de se analisar a colonialidade e compreender suas formas atualizadas de controle, para que possamos repensar a educação ambiental. Segundo a autora e o autor: 
[...] a Educação Ambiental [...] vem produzindo uma narrativa em seu movimento educativo-ambiental, defendendo que é importante considerar, em suas análises e práticas, as relações com o lugar, com as comunidades e as culturas compartilhadas. Além disso, é preciso reconstruir nosso sentimento de pertencer à natureza em estreita relação com a cultura. Portanto, descolonizar ensejos das dicotomias, das dogmatizaçôes e das essencializaçôes criadas no pensamento colonial moderno são problematizaçôes que nos levam a repensar a EA (Tristão \& Vieiras, 2017, p. 105).

Dialogando com nossa pesquisa, observamos que a autora e o autor desenvolvem seus estudos em uma perspectiva que se aproxima de uma concepção decolonial, ao ressaltarem a potência das reexistências produzidas pelas narrativas, que podem ser carregadas de experiências culturais. Nessa concepção, a educação ambiental pode se mover molecularmente articulada às comunidades que destacam a importância de preservar seus hábitos e costumes ancestrais de vivenciar as naturezasculturas locais.

Em nossa pesquisa, nas tentativas de seguir esses fluxos, encontramos coletivos - grupos auto-organizados e sem hierarquias, formados por estudantes da universidade - que podem compor currículos com as comunidades e promover possíveis revoluçôes moleculares na emergência de uma subjetividade ecocoletiva.

\section{ARTICULAÇÃO TEÓRICO-METODOLÓGICA NAS COMPOSIÇÕES CURRICULARES POSSÍVEIS}

Assim, nesse movimento de pensar nas composiçôes curriculares, encontramo-nos com: Alves (2001), que compreende os espaçostempos escolares como dimensão material do currículo; Ferraço \& Carvalho (2013), que nos lançam a pensar em um currículo em redes; Gallo (2013), que problematiza o currículo como máquina de subjetivação; e Tristão (2013), que nos possibilita entender como a educação ambiental pode se entremear nessa concepção. Em comum, as perspectivas que essas autoras e autores abordam rompem com a estrutura tradicional, que compreende que o currículo é dicotômico e delimitado, permitindo-nos pensar "além".

Alves é uma pesquisadora potente no campo do cotidiano escolar. Dentre os seus vários artigos/estudos, um deles (Alves, 2001) provoca pensamentos sobre a concepção das composiçóes curriculares. No texto, a autora utiliza quatro imagens como espaçotempo para a discussão sobre o cotidiano da escola e os múltiplos currículos que ali são criados e estão em permanente disputa. Nas imagens que a autora apresenta, observamos diferentes reações quanto ao comportamento de alunos em situações de "cola", como o ato de se contorcer para esconder a resposta e, em outras situações, o compartilhamento, às vezes intencional, que a autora associa a um possível ato de solidariedade. Independente das possíveis opinióes quanto à "cola”, a autora ressalta a arte da estética na composição de pistas para compreender o que acontece naqueles espaçostempos:

Aquele olhar de lado que se repete, ainda hoje e sempre, se uma situação de prova se apresenta, continua levando a posiçốes de corpos muito parecidas às vistas nas imagens mostradas. Vale a pena prestar atenção, observar, estudar, analisar e compreender situações iguais a estas para entender melhor nossas redes cotidianas de aprenderensinar e as maneiras como são tecidos os currículos no dia a dia das escolas e das salas de aula (Alves, 2001, p. 9).

Nesse sentido, a autora nos provoca a observar as situaçôes singulares que ocorrem a todo momento e a potência que as acompanha. Em nossa pesquisa, durante o doutorado em Educação, também procuramos observá-las, o que nos auxiliou a entender as relaçôes comunitárias e solidárias que eram tecidas na composição dos currículos, como olhares, sorrisos e afetos nos encontros conversa-evento-formação. ${ }^{8}$

Um outro bom encontro' foi com Ferraço \& Carvalho (2013) que, em um agenciamento coletivo com Deleuze, Guattari e vários outros autores e autoras, nos auxiliam nessa jornada, ao apostarem em um currículo rizomático, que se articula em redes, como projeto ético-estético-político aberto à invenção e à experiência:

Nesse sentido, pensar currículos em redes implica pensar o conhecimento e a aprendizagem a partir de agenciamentos coletivos que se produzem em meio à multiplicidade e a processos de relaçóes não hierárquicas 
inseridas no cotidiano escolar. Do mesmo modo, os currículos em redes, dentre os seus pressupostos, apontam que: o cotidiano não é uma instância específica da realidade social e, nesse sentido, afirma a indissociabilidade entre diferentes modos de inserção no mundo em seus diferentes processos (global, estatal, local, doméstico, de produção, etc.), ou seja, considera a impossibilidade de dissociar a vida cotidiana em sua micropolítica das estruturas macrossociais, em seus saberes, fazeres, valores e interesses dominantes; o campo dos poderes, saberes, fazeres é rizomático, portanto sem dicotomia entre diferentes formas de saber e fazer; a teoria é limite e horizonte da prática; o coletivo e a comunidade podem engendrar modos alternativos híbridos de intervenção sobre o social (Ferraço \& Carvalho, 2013, p. 145).

$\mathrm{Na}$ concepção que dialogam, o currículo compreende toda a dinâmica que o cerca, como: os diálogos cotidianos, o currículo como com-posição que implica a disposição em acolher a palavra do outro; a práticateoriaprática como política curricular e de conhecimento no cotidiano da escola e na pesquisa acadêmica; os engendramentos maquinicos na produção de subjetivação; a influência do colonialismo na dominação epistemológica (saber-poder); as ressonâncias culturais e afetivas; a característica de se organizar em redes e não em organogramas; a indissociabilidade dos campos epistemológico, político, cultural e ambiental; e a inclusão das dimensôes vitais na produção de conhecimento.

Assim, ao pensarmos nessa perspectiva, podemos refletir sobre a potência das composiçóes curriculares que acontecem, as formas de pensar e agir e os efeitos e ressonâncias que podem suscitar.

Nessa mesma obra que Ferraço e Carvalho organizam, encontramos o texto de Gallo (2013) que desenvolve problematizações em conexão com Guattari. Segundo o autor:

Um processo contemporâneo de singularização, de constituição de si mesmo no coletivo, passa pela resistência a essa subjetivação capitalística, que investe na mesmidade individualizada, reafirmando a possibilidade da diferença, da variação, da metamorfose. Se o currículo é máquina de subjetivação, operando na conformidade com a sociedade capitalística, é também campo de conflitos, de resistência, de variação. Se o currículo é tomado por uma escola-aparelho-de-Estado, também pode ser instrumento para uma escola-máquina-de-guerra (Gallo, 2013, p. 216-217).

Ao dialogarmos com o autor e conceber o currículo como uma máquina de subjetivação, entendemos os nomadismos que podem ocorrer. Para Deleuze \& Guattari (1997, p. 53) o nômade constitui ou busca constituir territórios com potência de transformação coletiva, de modo que, o nomadismo não tem a ver com deslocamento físico, mas intensivo:

E nesse sentido que o nômade não tem pontos, trajetos, nem terra, embora evidentemente ele os tenha. Se o nômade pode ser chamado de o Desterritorializado por excelência, é justamente porque a reterritorialização não se faz depois, como no migrante, nem em outra coisa, como no sedentário (com efeito, a relação do sedentário com a terra está mediatizada por outra coisa, regime de propriedade, aparelho de Estado...). Para o nômade, ao contrário, é a desterritorialização que constitui sua relação com a terra, por isso ele se reterritorializa na própria desterritorialização. É a terra que se desterritorializa ela mesma, de modo que o nômade aí encontra um território.

Nesse sentido, desenvolvemos que os currículos escolares, por compreenderem subjetividades, movimentam desterritorializaçôes e, em diálogo com os autores, podemos criar possibilidades de pensar em subjetividades ecocoletivas na composição de currículos nômades em meio às tentativas de controle e capturas da máquina da colonialidade.

Para essa conversa, buscando entremear a questão para a educação ambiental, aproximamo-nos de Tristão (2013, p. 853), ao afirmar:

O currículo emerge como uma história mais aberta, perceptor de uma organicidade sincronizada em que natureza e cultura estão em interação, guiado por uma abordagem integrativa e ecológica, podendo abarcar escolhas significativas dos sujeitos aprendentes em uma reflexão sobre o lugar, a tradição, a cultura. As lin- 
guagens são carregadas de significados e as palavras têm histórias e preconceitos, como é o caso do sentido atribuído à natureza, à cultura e à tradição, bem como as marcas deixadas pela e por meio da tradição no caso. As comunidades locais, com seus saberes sustentáveis, possuem suas culturas cotidianas, comuns, corriqueiras e tradicionais, mas também participam da cultura global.

Assim, podemos observar as possibilidades de pensar o currículo nessa concepção, em um campo de tensôes e contradiçóes, como é a escola e a comunidade que o contextualizam. As complexidades que permeiam esse campo necessitam de uma abordagem mais aberta a esses acontecimentos e relaçóes. Nesse contexto, em conexão com as autoras e autores, buscamos produzir pistas para essa cartografia, onde buscamos as possibilidades de atravessamentos da educação ambiental nos currículos nômades.

\section{CARTOGRAFIA DOS MOVIMENTOS DE CRIAÇÃO E INVENÇÃO NOS COTIDIANOS ESCOLAR-COMUNITÁRIOS}

A cada dia observamos como a vida é complexa e instável ao nos depararmos com as situações cotidianas até as grandes catástrofes socioambientais, sem compreender a conexão que pode haver entre elas. Tal desconhecimento tem o potencial de nos descontextualizar da rede da vida, que mais pode se assemelhar a um novelo de lã devido às forças maquinicas que atuam sobre elas.

Trata-se, assim, de um emaranhado de linhas, todas entrelaçadas e envolvidas, que podem ser atravessadas por linhas de fuga destoantes do modelo e ressoantes pelos territórios. Linhas que podem criar rotas de fuga em meio às forças externas de domínio e adequação. Assim, imaginamospensamos que não se trata de sujeitar e controlar as linhas rebeldes, resistentes e singulares - uma vez que sempre reexistirão - mas de cartografar, compor com elas. Talvez assim poderíamos fugir de nossa passividade fatalista.

Em nossas experiências, sempre que tentamos controlar os territórios escolares - a pesquisa, a aula, o currículo - podemos observar linhas fugidias que seguem em outras direçôes, talvez em fluxos de reexistências. Em diálogo com Deleuze \& Guattari (2011a, 2011b), entendemos que esses fluxos podem se articular por territórios conhecidos, ou não, e criar possibilidades de mundos possiveis, independentemente de haver forças de controle.

A química e escritora Stengers (2015, p. 91) também compõe com esse pensamento, ao propor “[...] associar os comuns com uma capacidade de resistência, com possibilidade de reapropriação das capacidades de pensar e agir conjuntamente", mostrando-nos uma possível tendência nas práticas sociais em que, além de resistir, questionar e criticar, podem criar possibilidades como encontramos nas pesquisas de Negri \& Guattari (2017). Os autores entendem que a singularidade, autonomia e liberdade são as linhas de aliança que surgem nos movimentos contemporâneos. Movimentos que destoam do coletivismo cego, redutor e repressivo, além do igualitarismo abstrato. E são esses movimentos que procuramos pesquisar, na possibilidade de cartografar a criação e invenção de currículos nômades nos cotidianos escolar-comunitários.

Com essa compreensão, dialogamos também com Tristão (2013, p. 847), que compreende a educação ambiental como "[...] filosofia de vida e não como uma disciplina obrigatória que se soma às outras disciplinas de um currículo ou a um tema”. A autora aposta em uma educação ambiental “[...] como uma orientação para conhecer e compreender em sua complexidade a natureza e a realidade socioambiental” (Tristão, 2013, p. 847), que podemos relacionar com as possibilidades de suscitar os movimentos criativos/inventivos.

Assim, devido às complexidades que irrompem a pesquisa, a opção teórico-metodológica pela cartografia, com intercessão de Deleuze \& Guattari (2011b), pareceu mais interessante, pois nos possibilitou experimentar ao invés de planejar. Pensar a pesquisa e o currículo como uma experimentação - assim como Godoy (2015) realiza nos estudos em educação ambiental - requer abrir mão dos resultados esperados e se abrir para o inesperado. Também dialogamos com a pesquisa de Tristão (2013, p. 857), ao propor “[...] acatar o imprevisível em sua trajetória”. A autora também problematiza que: 
No paradigma dominante da ciência moderna, os fatos precisam ser medidos ou pesados. Mas as relaçôes sociais e humanas com o meio ambiente e uma perspectiva socioecológica da educação e do desenvolvimento não podem ser medidas nem pesadas; podem ser mapeadas ou cartografadas. Então, assumimos uma mudança, quando se trata da pesquisa em educação ambiental, em vez de medir, cartografar e narrar. A intenção é contribuir para um campo de pesquisa que vá além de um método e de uma metodologia de dimensões discursivas/políticas/filosóficas que orientam a investigação (Tristão, 2013, p. 852).

Assim, a autora sugere pensar a pesquisa mais aberta às conexôes que podem surgir, uma vez que "[...] a educação ambiental, como uma antidisciplina, não pode se fechar a uma razão única, pois ela se sustenta em uma racionalidade mais aberta" (Tristão, 2013, p. 850). Nesse sentido, a cartografia que produzimos na pesquisa de doutorado é ancorada nos princípios rizomáticos de Deleuze \& Guattari (2011b), uma vez que tanto a perspectiva da educação ambiental que dialogamos, quanto os movimentos de reexistências que buscamos pesquisar podem ser relacionados com o rizoma em suas articulaçóes no contexto da universidade e para além dela.

Para os autores (Deleuze \& Guattari, 2011b), o rizoma, pelos seus princípios - conexão, heterogeneidade, multiplicidade, ruptura assignificante - só poderia ser cartografado como uma paisagem ainda desconhecida, pois é aberto e conectável em todas as suas dimensóes. Essa perspectiva requer o desafio de "pensar pelo meio", como Stengers (2015) em diálogo com Deleuze desenvolve, e "[...] realizar uma reversão do sentido tradicional de método" (Passos \& Barros, 2010, p. 17). Ou seja, se, no método tradicional de pesquisa, é necessário primeiro partir de metas planejadas para então ir ao campo de pesquisa, na cartografia, é a própria trajetória durante a pesquisa que fornecerá as pistas que irão orientar o percurso.

Barros \& Barros (2014) também nos auxiliam, nesse sentido, com a pista da análise na pesquisa cartográfica. Segundo as autoras, na pesquisa tradicional se fala da análise dos dados como uma das etapas a serem seguidas na produção de conhecimento e, na pesquisa cartográfica, a análise e a interpretação acompanham os fluxos do processo e permitem que a compreensão inicial passe por transformaçốes. Portanto, se, na pesquisa tradicional, os dados são coletados, na pesquisa-intervenção cartográfica, eles podem ser produzidos.

Nessa concepção, a análise na pesquisa cartográfica é feita por problematização, ou seja, o que move a análise na cartografia são os problemas. Assim, buscamos produzir pistas ao seguir esses movimentos pela universidade e além dela, acompanhando as redes de conversações e produzindo narrativas.

Neste texto, buscamos articular os dados produzidos na cartografia, durante o doutorado em Educação, ao acompanhar dez encontros-conversa (redes de conversação que aconteciam naturalmente) no campus da Universidade Federal do Espírito Santo (Ufes), localizado na cidade de Alegre/ES e três encontros-evento e encontros-formação ${ }^{10}$ organizados por movimentos coletivos que encontramos durante a pesquisa, ${ }^{11}$ Grupo Kapi'xawa e Movimento Kizomba (formados por graduandos da Ufes), que aconteceram nos espaços comunitários e escolares.

\section{CURRÍCULOS NÔMADES AS POSSIBILIDADES PARA A EDUCAÇÃO AMBIENTAL}

Diante de cenários cada vez mais desafiadores observamos nas comunidades escolares e acadêmicas, movimentos que possivelmente inventam currículos articulados às culturas locais, micropolíticas de reexistências e outros agenciamentos possíveis. Movimentos inventivos que podem ser compostos por coletivos auto-organizados e que atravessam as práticas cotidianas das escolas produzindo experiências. Escolas-comunidades estão entrelaçadas às relações locais e sofrem pressóes em suas existências, que são impactadas por questôes ainda coloniais de gênero, raça, etnia, deficiência e religião.

As experiências singulares que se entremeiam ao local/comum podem potencializar e influenciar as diferentes aprendizagens, como observamos nos projetos em articulação de coletivos com as escolas no município de Alegre/ES, onde observamos fluxos de desejo que ensejam composiçóes curriculares na busca por 
desenvolver conexôes com as culturas locais, facilitação de redes de compartilhamento de saberes socioambientais comunitários, organização de encontros-formação-evento, dentre diversas ações, que sugerem possibilidades para a invenção de currículos nômades.

Com a tentativa de seguir os fluxos de produção curricular, observamos composições que, potencializam uma educação ambiental decolonial e produzem pistas nas trajetórias cartográficas: na aproximação às questôes socioambientais e organização de encontros-conversa-formação-evento, junto a processos de criação de escolas com práticas de sustentabilidade que vão além dos programas prescritos e/ou oficiais. Esse ensejo movimenta o pensamento e produzem em sua micropolítica, importantes composiçóes com a cultura local e com saberes comunitários/colaborativos que se aproximam de uma perspectiva nômade e que pode “recriar a capacidade de pensar e agir juntos" (Stengers, 2015, p. 148).

Nos encontros-formação que acompanhamos (organizados pelo Grupo Kapi'xawa sobre Agroecologia e articulados com a comunidade), nas rodas de conversa, observamos a produção coletiva de conhecimentos. Pensamos que essa busca por conhecimentos que tentam escapar das engrenagens individualistas/ consumistas da máquina da colonialidade, também podem nos auxiliar a produzir pistas que dialogam com Stengers (2015, p. 14-15), ao problematizar sobre os que buscam fugir dessa "guerra suja” econômica:

Se estamos em suspenso, alguns já estão engajados em experimentações que buscam criar, a partir de agora, a possibilidade de um futuro que não seja bárbaro - aqueles e aquelas que optaram por deserdar, por fugir dessa 'guerra suja' econômica, mas que, 'fugindo, procuram uma arma', como dizia Gilles Deleuze. E, aqui, 'procurar' quer dizer, antes de tudo, criar, criar uma vida 'depois do crescimento econômico', uma vida que explora conexóes com novas potências de agir, sentir, imaginar e pensar.

Outras pistas também podem ser produzidas nas narrativas que parecem considerar a educação ambiental como uma dimensão, onde as dicotomias criadas pela máquina da colonialidade, dentre outros engendramentos, podem ser desterritorializadas e reterritorializadas pelas relaçóes múltiplas e singulares, na teia bumanonaturezacultura:

Na escola, eu entendia que educação ambiental era preservar o planeta. Era isso que eu entendia. Via educação ambiental como o ensino para a gente compreender como a gente deve preservar o planeta, mas conectando com a Agroecologia e, depois, na universidade, graduando em Geologia, eu comecei a entender, e hoje eu tenho uma visão da educação ambiental mais ampla e diferente (Encontro-conversa 7). ${ }^{12}$

Então eu acho que a educação ambiental fica muito presa no viés de preservação e, na verdade, eu vejo que o caminho da educação ambiental é a ideia de fazemos parte do todo. Para mim, essa é a transformação que a gente precisa na educação ambiental (Encontro-conversa 7).

Como os bons encontros dos coletivos com as escolas-comunidades, que criam experimentaçôes (Figura 1) ${ }_{13}^{13}$ exploram formas coletivas de agenciar o meio ambiente, onde, professores(as) e alunos(as) criam rodas de conversa sobre suas vivências e relaçóes com a teia socioambiental. Durante as rodas, também ocorrem formações sobre as formas de se relacionar com às naturezasculturas; reflexóes sobre o exagerado consumismo; reutilização e destinação de embalagens e produtos, materiais descartados; higienização de frutas e legumes para consumo e segurança alimentar; entre outras questóes que emergiam nos fluxos das discussões. 


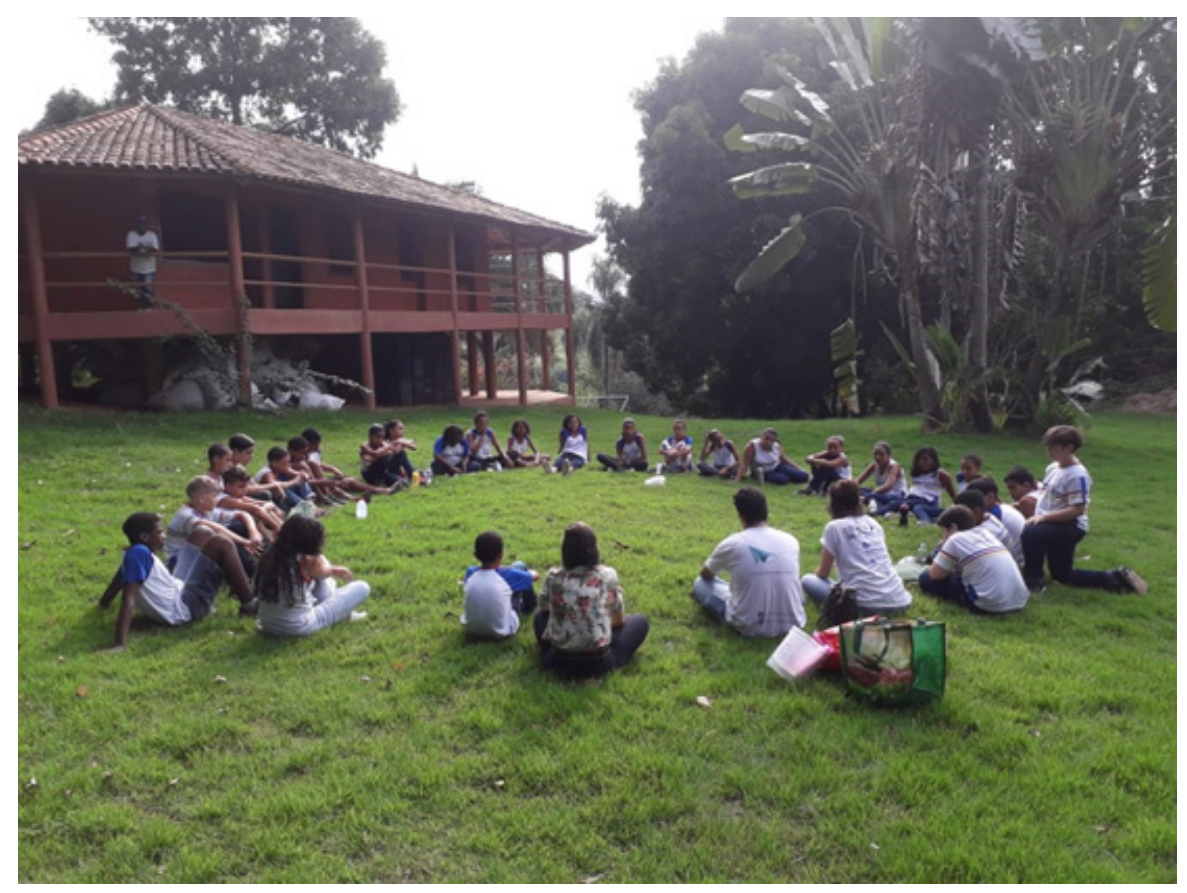

Figura 1. Experimentação nas rodas de conversa.

Nessa experimentação, estudantes da Educação Básica e graduandos da Ufes tiveram a oportunidade de produzir subjetividades ecocoletivas nas conversas, buscando por alternativas mais sustentáveis para viver. Alguns estudantes relataram que seus familiares trabalhavam na Associação dos Catadores de Materiais Recicláveis do Município de Alegre (Ascoma), compartilhando suas vivências e experiências.

Outro acontecimento que emerge como potência nos fluxos de produção curricular, organizado pelo Grupo Kapi’xawa, é o Encontro da Consciência do Caparaó (ENCO), com 11 edições já realizadas. A 11ạ edição - que ocorreu entre os dias 9 e 15 de setembro de 2019, no Sítio Floresta, localizado no Assentamento Rural Floresta em Alegre/ES - trouxe como tema "O Planeta Terra é o nosso Meio Ambiente, nossa Casa Comum”. Esse encontro, que acontece anualmente na Região do Caparaó, reúne diversos saberes populares e científicos, a fim de compartilhar e difundir práxis importantes para uma reconstrução das relações humano-natureza-cultura, inspirados na Agroecologia e na Permacultura. Nessa edição, dentre as diversas formações, atividades e oficinas, destacamos a oficina sobre Plantas Alimentícias Não Convencionais (PANCs) a alunas e alunos da escola rural do Assentamento Floresta em um registro fotográfico (Figura 2). 


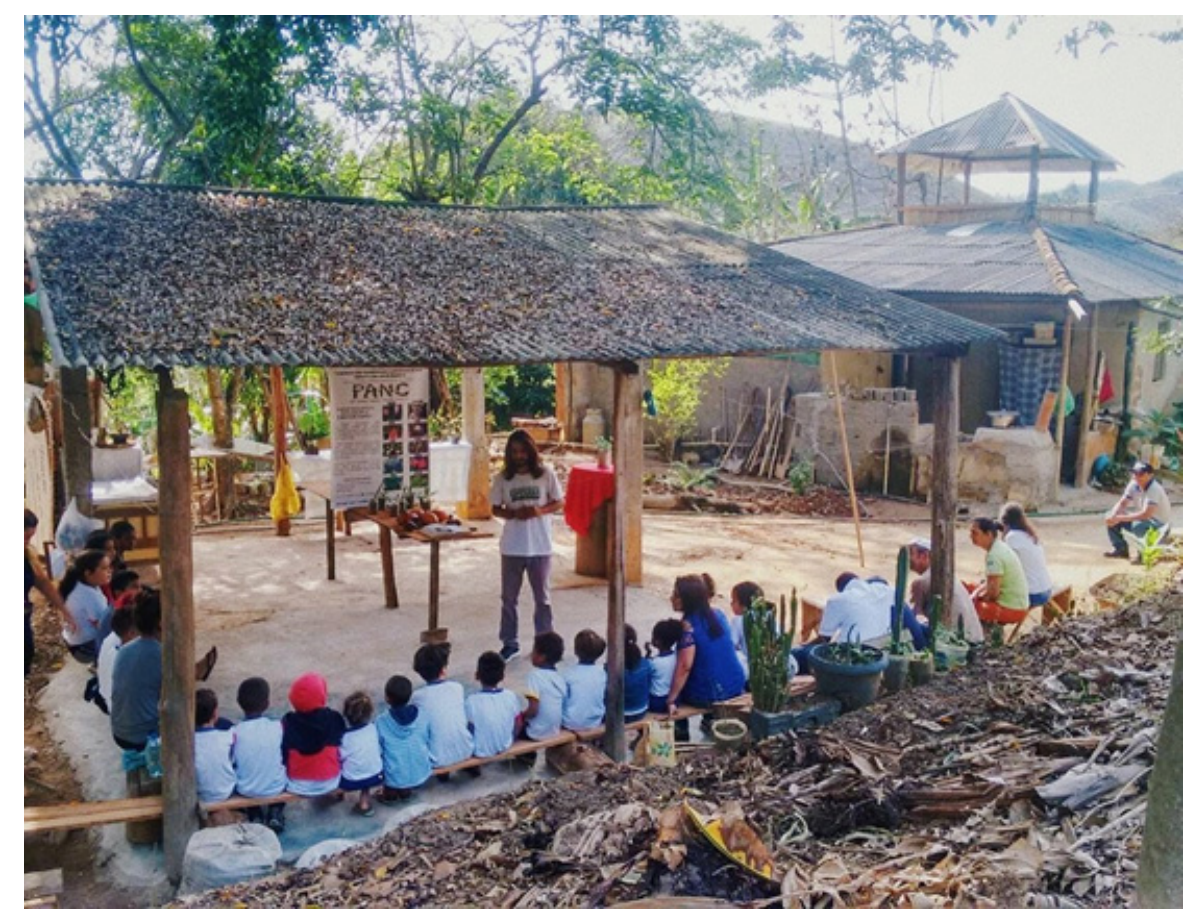

Figura 2. Oficina sobre Plantas Alimentícias Não Convencionais (PANCs).

Durante esse importante encontro-formação, a articulação entre escola-universidade-comunidade pode ser potencializada na socialização de conhecimentos daquela comunidade aos jovens estudantes, que muitas vezes não fazem parte dos conteúdos programáticos. A esses acontencimentos associamos a criação dos currículos nômades, que se potencializam nas desterritorializaçôes.

Outro coletivo que se entremeia aos movimentos de reexistências e que encontramos nesta cartografia é o Movimento Kizomba. Em suas composições curriculares, também podem potencializar o atravessamento rizomático da educação ambiental e, em alguns processos, talvez suscitar fluxos descolonizadores. Nas conexôes que promovem na universidade e nas comunidades, eles se manifestam como força ativa no campus, produzindo talvez micropolíticas de reexistências.

Em 15 de maio de 2019, os coletivos movimentaram o campus na organização de movimentos em defesa das IES públicas. Essa manifestação foi a culminância de encontros-conversas que já estavam ocorrendo na universidade, nas redes de conversaçôes e micropolíticas de reexistências, em meio aos constantes cortes na educação pelo atual governo de extrema-direita, promovendo rupturas com os mecanismos de controle e desarticulação na universidade. Nas enunciaçôes coletivas, evocam: "Precisamos lutar para existir! " (Encontro-conversa 10).

Além disso, observamos alguns tracejados nas formações micropolíticas que podem potencializar a singularidade, a potência de ser molecular, múltiplo - não supor nenhuma unidade ou totalidade e nunca ser remetido a um sujeito: "[...] uma juventude inteira lutando para a gente conseguir transformar o nosso amanhã, e até mesmo o nosso hoje, em uma sociedade que a gente possa falar sem medo de ser reprimido" (Encontro-conversa 5).

Para Guattari (1987), é esse movimento que potencializa o múltiplo, o coletivo. Assim, os agenciamentos coletivos de enunciação podem produzir mais pistas para a composição dessa cartografia da singularidade dos coletivos, uma vez que, segundo o autor:

A consistência precede a existência. O acontecimento singular da 'tomada de consistência' gera os tempos, os espaços e as substâncias próprias dos agenciamentos. Enquistadas, teleguiadas ou em estado livre - isto é, no estado de perpétuo nascimento -, são as singularidades que produzem territórios desterritorializando outros, que inventam novos agenciamentos, que secretam processos inéditos de semiotização e de subjetivação. Estão na raiz dos agen- 
ciamentos de enunciação antes mesmo de qualquer coordenada desenvolvida, que qualquer produção tenha sido programada. Só a singularidade é criadora de processo singular, isto é, de história (Guattari, 1987, p. 163).

Nesse movimento de desterritorialização, talvez ensejado pela "tomada de consistência", os coletivos potencializaram/potencializam a composição de currículos nômades, que atravessaram/atravessam as paredes da universidade e das escolas, ao organizarem encontros-eventos com as comunidades como o que aconteceu no dia 14 de dezembro de 2019, no início das férias da universidade. Enquanto vários estudantes já se preparavam para retornar às suas casas e dar início a viagens, os movimentos se articularam para organizar um potente encontro-evento em conexão com a comunidade de Alegre/ES. Com o título "I Festival de Diversidade e Direitos Humanos de Alegre" e com o enredo "Cuidar é um ato político", criaram rodas de conversa, oficinas, atraçóes culturais e feirinha com aqueles e aquelas que compóem as escolas-comunidades.

Nas composiçốes curriculares criadas nesse encontro-evento, destacamos a possibilidade de atravessamento de uma educação ambiental decolonial nas oficinas culturais infantis, que abordaram a cultura indígena, na tentativa de resgatar resquícios de tradiçốes culturais dos povos Guarani que viveram e os que ainda reexistem na região do Caparaó. ${ }^{14}$ Ressaltamos, também, a oficina Abayomi, ${ }^{15}$ que, em articulação com membros da comunidade negra de Alegre/ES, trouxe a arte como reexistência, que observamos na tentativa de recriar a cultura ancestral africana no contexto da escravização/colonização, por meio da confecção das bonecas, narrando o momento em que elas eram produzidas a partir das vestimentas características das diferentes aldeias em que as famílias eram retiradas e separadas.

Além dessas potentes oficinas que aconteceram no encontro-evento, destacamos, também, a oficina do projeto "Capoeira da Angola e Educação Ambiental” em um entrelaçamento entre a dança-luta de reexistência e a dimensão da educação ambiental.

Nesse projeto voluntário do coletivo com a comunidade, observamos que pode haver potentes agenciamentos ecocoletivos que permitem o atravessamento molecular da educação ambiental decolonial, como quando envolvem crianças e jovens da comunidade, produzem cantos culturais e recriam a luta juntos:

Oh, era eu era meu mano, era meu mano era eu.

Era eu era meu mano, era meu mano era eu.

Era eu era meu mano, quando nós andava junto.

Era eu era meu mano, quando nós travamo uma luta.

Era eu era meu mano, ele não venceu nem eu.

Era eu era meu mano, era meu mano era eu.

Foi no balanço foi no remelexo eu vi o siri derrubar o caranguejo.

Foi no balanço foi no remelexo eu vi o siri derrubar o caranguejo.

Foi no balanço foi no remelexo eu vi o siri derrubar o caranguejo.

Adeus adeus, a deusa, vou me embora com as ondas do mar.

Eu vou me embora com as ondas do mar.

Vou me embora saudar Iemanjá.

(Cantos na roda de capoeira)

Nos cantos entoados, podemos observar as conexôes na teia socioambiental, onde os humanos ora são como seu semelhante "era meu mano era eu"; ora como animais "Foi no balanço foi no remelexo eu vi o siri derrubar o caranguejo"; ora como a natureza "Eu vou me embora com as ondas do mar”. A dança-luta, assim como os cantos, possibilitam o atravessamento da cultura africana na formação, oportunizando desterritorializações do conhecimento eurocentrado e a reterritorialização dos conhecimentos apagados/negligenciados - como denunciam Quijano (2005) e Bernadino-Costa, Maldonado-Torres \& Grosfoguel (2019). Os movimentos, ao promover essas aprendizagens, podem produzir pistas dos nomadismos curriculares. 
Nas enunciações coletivas e narrativas produzidas em nossa pesquisa, os coletivos ressaltam os agenciamentos que talvez sejam/são potencializados nessa relação:

A gente vê, assim, a capoeira angola totalmente interligada com a educação ambiental, porque a capoeira ela é a natureza assim... Todos os movimentos são baseados na natureza, pelo ponto de vista mais amplo, mais holístico. Tal como o 'Tai Chi Chuan' que é uma arte chinesa. Que faz movimentos fluidos assim... Então a capoeira angola parte desse pressuposto. Assim, 'seguindo o balanço do mar', toda essa questão da fluidez do corpo e do diálogo corporal. Ela veio da África, trazida pelos negros e negras, do povo preto que veio para cá escravizado. E lá na África já tinha, assim, algumas práticas que não eram exatamente a capoeira, mas que aqui, no Brasil, deram origem à capoeira como uma luta de libertação. E aí a gente usa ela para o ser humano - para as crianças assim no caso que a gente trabalhava, mas também para todas as pessoas - traz assim um maior entendimento da sua identidade, da sua história. Ainda mais nós, como brasileiros, isso está diretamente no nosso DNA. E hoje a capoeira está no mundo todo. O instrumento principal da capoeira hoje, que é o berimbau, ele é praticamente feito de coisas da natureza [...]. E através da capoeira a gente consegue trazer o entendimento geral da pessoa no ambiente, na relação com outras pessoas [...]. Para a educação ambiental, a gente traz essa questão do respeito com o outro, com a natureza, a que tudo está ligado. Na capoeira angola, é um diálogo corporal. Ali que a gente fala de pergunta e resposta. Então, se você tem uma pergunta agressiva, muitas vezes você recebe uma resposta agressiva também, ou não, porque é um diálogo, então ele segue. E aí tem tudo a ver (Encontro-conversa 10).

Nesse agenciamento coletivo de enunciação, podemos pensar com Negri e Guattari. Quando os agentes coletivos enunciam a capoeira como uma "luta de libertação", isso nos permite dialogar com Negri \& Guattari (2017), que refletiram sobre por onde podem fluir as engrenagens das máquinas de luta: por novos espaços de liberdade.

Em outro movimento, ao associarem a capoeira a um diálogo, em que perguntas agressivas podem gerar respostas agressivas, ou não, podemos compor com Stengers (2015), ao problematizar qual será a nossa resposta à intrusão de Gaia. Mesmo sendo Gaia: “[...] um suscetível agenciamento de forças indiferentes aos nossos pensamentos e aos nossos projetos” (Stengers, 2015, p. 41), cabe-nos criar respostas a esse diálogo que nos encaminhem a um destino que não seja bárbaro. Nesse contexto, podemos pensar que os movimentos talvez suscitem novas potências de pensar e agir que podem fluir nos diálogos corporais.

Também produzimos pistas ao observar que, mesmo sem apoio econômico e institucional, os movimentos se articulam criando possibilidades em meio aos impasses e cristalizaçóes da máquina da colonialidade. Assim, podemos dialogar com Deleuze \& Guattari (2011a, p. 499) sobre a potência das linhas de fuga: "Eis por que as linhas de fuga são singularmente criadoras e positivas: elas constituem um investimento social tão completo e total quanto o investimento contrário”.

Ao cartografar os fluxos de produção curricular nas conexões com as escolas-comunidades nos encontros conversa-evento-formação, problematizamos que talvez possam produzir subjetividades ecocoletivas e criar possibilidades para potencializar currículos nômades. Que pode nos fornecer pistas de invenção do comum e compreender o atravessamento de uma educação ambiental decolonial para além da escola-universidade.

\section{CONSIDERAÇÕES FINAIS}

Nos potentes agenciamentos ecocoletivos e composições curriculares nômades - que rompem com o conhecimento fechado em disciplinas e se abrem ao desconhecido - problematizamos as possibilidades para uma educação ambiental em conexão com as escolas-comunidades, que podem atravessar uma educação ambiental decolonial.

Assim, ressaltamos essas práticas transgressoras e inventivas para articular currículos nômades, como possibilidade de fugir das formas de controle que se entremeiam aos atuais documentos e políticas educacionais. Currículos que são produzidos nos cotidianos escolares e comunitários, ricos em experiências e saberesfazeres, muitas vezes invisibilizados nas referências oficiais, mas que reexistem nos mundos possiveis que podemos criar. 
Nesse sentido, apostamos no atravessamento de uma educação ambiental múltipla, nômade e revolucionária que, imbricada às micropolíticas de reexistências, como uma experimentação, pode atravessar currículos nômades. Aquela que se articula com os movimentos sociais e com a cultura local, tece fluxos de produção curricular e que reexiste nas instituições de ensino, mesmo que tentem estrangulá-la em disciplinas e ações esporádicas, pois acreditamos que a maioria de suas ressonâncias são informais e transgressoras.

A educação ambiental, em uma perspectiva decolonial, pode promover fluxos desejantes, que se articulam aos espaçostempos das escolas-universidades e para além delas, pois é maquinica, transversal e multidimensional. É como uma máquina desejanteambiental, engendrando fluxos desejosos de naturezasculturas.

Uma máquina desejanteambiental que pode, talvez, ser potencializada pelos movimentos inventivos como os que pesquisamos. Movimentos que podem se articular como máquinas de luta em meio a um contexto de desmonte e tentativas de controle pela máquina da colonialidade, lutando por novos espaços de liberdade, seja na escola, seja fora dela.

E agora, nesse mundo pandêmico, onde o colapso ambiental é uma realidade, precisaremos ser ainda mais criativos e apostarmos em movimentos inventivos que suscitem por novas potências de agir e sentir com a teia socioambiental.

\section{AGRADECIMENTOS}

O CECIMIG agradece à CAPES (Coordenação de Aperfeiçoamento de Pessoal de Nível Superior) e à FAPEMIG (Fundação de Amparo à Pesquisa do Estado de Minas Gerais) pela verba para editoração deste artigo.

\section{REFERÊNCIAS}

Alves, N. (2001). Imagens das escolas: sobre redes de conhecimentos e currículos escolares. Educar, 17, 53-62. https:// doi.org/10.1590/0104-4060.219

Barros, L. M. R. \& Barros, M. E. B. (2014). Pista da análise: o problema da análise em pesquisa cartográfica. In E. Passos, V. Kastrup \& S. Tedesco (Org.). Pistas do método da cartografia: a experiência da pesquisa e o plano comum, v. 2. Sulina.

Bernadino-Costa, J., Maldonado-Torres, N. \& Grosfoguel, R. (2019). Decolonialidade e pensamento afrodiaspórico. In J. Bernadino-Costa, N. Maldonado-Torres \& R. Grosfoguel (Org.). Decolonialidade epensamento afrodiaspórico (2a ed). Autêntica Editora.

Cheng, V. C. C., Lau, S. K. P., Woo, P. C. Y., \& Yuen, K. Y. (2007). Severe Acute Respiratory Syndrome Coronavirus as an Agent of Emerging and Reemerging Infection. Clinical Microbiology Reviews, 20(4), 660-694.

Deleuze, G., \& Guattari, F. (1977). Kafka: por uma literatura menor. Imago.

Deleuze, G., \& Guattari, F. (1997). Mil Platôs: Capitalismo e Esquizofrenia, v. 5. Editora 34.

Deleuze, G., \& Guattari, F. (2011a). O anti-édipo: capitalismo e esquizofrenia (2a ed). Editora 34.

Deleuze, G., \& Guattari, F. (2011b). Mil platôs: capitalismo e esquizofrenia, v. 1 (2a ed). Editora 34.

Espinosa, B. (2008). Ética. Autêntica Editora.

Ferraço, C. E., \& Carvalho, J. M. (2013). Lógicas de currículos em redes e projetos: entre equívocos e possíveis no cotidiano. In C. E. Ferraço \& J. M. Carvalho (Org.). Currículos, pesquisas, conhecimentos e produção de subjetividades (pp. 143-160). DP et Alii.

Foucault, M. Os corpos dóceis (1987). In M. Foucault. Vigiar e punir: nascimento da prisão. Vozes.

Gallo, S. (2013). Do currículo como máquina de subjetivação. In C. E. Ferraço, \& J. M. Carvalho (Org.). Currículos, pesquisas, conhecimentos e produção de subjetividades (pp. 203-217). DP et Alii. 
Godoy, A. (2015). Educação ambiental e filosofia prática: “Uma ou duas linhas e por trás uma imensa paisagem”. Rev. Eletrônica Mestr. Educ. Ambient., 4-19. https://doi.org/10.14295/remea.v0i0.4847

Gonzalez-Gaudiano, E. (2005). Educação ambiental. Instituto Piaget.

Guattari, F. (1987). Revolução molecular: pulsaçôes políticas do desejo (3a ed). Editora Brasiliense.

Guattari, F., \& Rolnik, S. (1996). Micropolitica: cartografias do desejo (4⿳亠丷a ed). Vozes.

Guimarães, L. B., \& Sampaio, S. M. V. (2014). Educação ambiental nas pedagogias do presente. Em Aberto, Brasília, 27(91), 123-134. http://dx.doi.org/10.24109/2176-6673.emaberto.27i91

Henning, P. C., Mutz, A. S. C., \& Vieira, V. T. (Org.). (2018). Educaçôes ambientais possiveis: ecos de Michel Foucault para pensar o presente. Appris.

Maturana, H. (2001). Cognição, ciência e vida cotidiana. Ed. UFMG (Humanitas).

Negri, A., \& Guattari, F. (2017). As verdades nômades: por novos espaços de liberdade. Autonomia Literária e Editora Politeia.

Passos, E. \& Barros, R. B.(2010). Pista 1: a cartografia como método de pesquisa-intervenção. In E. Passos, V. Kastrup \& L. Escóssia (Org.). Pistas do método da cartografia: pesquisa-intervenção e produção de subjetividades. Sulina.

Quijano, A. (2005). Colonialidade do poder, eurocetrismo e América Latina. In E. Lander (Org.). A colonialidade do saber: eurocentrismo e ciências sociais. Perspectivas latino-americanas. Consejo Latinoamericano de Ciencias Sociales (CLACSO).

Stengers, I. (2015). No tempo das catástrofes: resistir à barbárie que se aproxima. Cosac Naify.

Tajra, A. (2020). Austrália foi alertada bá 13 anos pela ONU sobre aumento de queimadas. https://noticias.uol.com. $\mathrm{br} / \mathrm{meio}$-ambiente/ultimas-noticias/redacao/2020/01/12/australia-foi-alertada-ha-mais-de-10-anos-sobre-aumentode-queimadas.html

Tristão, M. (2009). Um olhar sobre a educação ambiental no Brasil. Processo formador em educação ambiental: mudanças ambientais globais. Universidade Federal Rural de Pernambuco, 2, 65-115.

Tristão, M. (2012). A educação ambiental e a emergência de uma cultura sustentável no cenário da globalização. $R$. Inter. Interdisc. INTERthesis, 9(1), 207-222. https://doi.org/10.5007/1807-1384.2012v9n1p207

Tristão, M. (2013). Uma abordagem filosófica da pesquisa em educação ambiental. Revista Brasileira de Educação, 18(55), 847-860. https://doi.org/10.1590/S1413-24782013000400003

Tristão, M. (2016). Educação ambiental e a descolonização do pensamento. Rev. Eletrônica Mestr. Educ. Ambient., 2849. https://doi.org/10.14295/remea.v0i0.5958

Tristão, M. (Org.). (2018). A educação ambiental e o pensamento pós-colonial: narrativas de pesquisas. CRV.

Tristão, M., \& Vieiras, R. R. (2017). Decolonizar o pensamento: apontamentos e entrelaçamentos epistêmicos com a educação ambiental. Rev. Eletrônica Mestr. Educ. Ambient., 103-117. https://doi.org/10.14295/remea.v0i0.7145

\section{NOTAS}

1 O novo coronavirus é uma zoonose que pode ter surgido, segundo a Organização Mundial da Saúde (OMS), no final de 2019 no mercado de Wuhan (China), onde se comercializam animais silvestres vivos ou abatidos, o que é uma das maiores suposiçóes de contágio do vírus para os humanos, causando severa síndrome respiratória aguda, coronavirus 2(SARS-CoV-2).

2 Segundo Foucault (1987), o corpo dócil se faz na união de duas características principais: a utilidade em termos econômicos e a docilidade em termos de obediência política.

3 O conceito menoré articulado a partir da leitura de Deleuze e Guattari do pensamento de Kafka: "Uma literatura menor não é a de uma língua menor, mas antes a que uma minoria faz em uma língua maior” (Deleuze \& Guattari, 1977, p. 25). 
4 Como uma imbricação entre os conceitos, onde um não pode ser dissociado do outro, Alves (2001) desenvolve uma concepção com a qual também dialogamos neste texto. Assim, a autora observa o espaçotempo escolar como dimensão material do currículo, composto de relaçôes múltiplas entre múltiplos sujeitos, com saberes múltiplos, que aprendem/ ensinam o tempo todo múltiplos conteúdos de múltiplas maneiras.

5 O Núcleo Interdisciplinar de Pesquisas e Estudos em Educação Ambiental (Nipeea) foi criado em 2005 e emergiu da necessidade de integração entre projetos que envolvem ensino, pesquisa e extensão, com vistas à consolidação de um grupo formado por professoras/es; alunas/os dos cursos de graduação, do Mestrado e Doutorado em Educação, do Programa de Pós-Graduação em Educação (PPGE/Ufes) e de egressas/os interessadas/os.

6 O Grupo Pesquisador em Educação Ambiental, Comunicação e Arte (Gpea) possui diversas experiências de pesquisa com vivências nos três biomas do Estado do Mato Grosso (Amazônia, Pantanal e Cerrado), com foco na educação popular, especialmente com pequenas comunidades, considerando suas ofertas escolares. A partir de 2014, o grupo tem se dedicado à crise climática, envolvendo pessoas com deficiências, quilombolas, indígenas, mulheres negras, crianças, professores, adolescentes, LGBTQ+, pescadores, mariscadoras, rendeiras, pequenos agricultores e diversos migrantes, entre outros grupos relacionados com o contexto de justiça climática.

7 Tristão (2016), ao dialogar com Ballestrin e outros autores latino-americanos, articula reflexôes sobre os mecanismos de controle que prevalecem na modernidade. Se, no passado, houve o processo de colonização; na modernidade, prevalece o processo de colonialidade.

8 Chamamos de encontro-conversa, encontros-evento e encontros-formação a culminância do acompanhar das redes de conversaçôes (Maturana, 2001). Os momentos em que nos encontramos e conversamos nos espaçostempos da pesquisa.

9 Segundo Espinosa (2008), os bons encontros são momentos em que nos tornamos mais próximos do mundo e de nós mesmos, ampliando a nossa capacidade de afetar e ser afetado.

10 Todos os encontros aconteceram e continuam a acontecer com iniciativa dos(as) estudantes que compóem os coletivos, o envolvimento da pesquisadora foi acompanhar, observar e relacionar aos estudos desenvolvidos no doutorado.

11 Ao longo da pesquisa de doutorado, foram acompanhadas cerca de 100 pessoas que compóem as comunidades escolares, acadêmicas e locais.

12 Esses encontros ocorreram durante a pesquisa no ano de 2019 com estudantes do campus de Alegre da Ufes que colaboravam e participavam de coletivos.

13 Experimentação que aconteceu em abril de 2019 com articulação do Grupo Kapi’ xawa com o Projeto de Extensão da Ufes, Laboratório de Estudos e Pesquisas em Educaşão Ambiental (Lepea), com alunas e alunos da Escola Municipal Pedro Simão, na Área de Relevante Interesse Ecológico (Arie) Laerte Paiva Gama, em Alegre/ES.

$14 \mathrm{Na}$ Região do Caparaó Capixaba, que antes era habitada por várias tribos indígenas (que influenciaram vários nomes de locais na região), atualmente há apenas poucas famílias que ainda sofrem perseguição para se retirarem do Parque Nacional do Caparaó, por se tratar de uma unidade de conservação.

15 Em Iorubá (uma das maiores etnias do continente africano, cuja população habita parte da Nigéria, Benin, Togo e Costa do Marfim) significa "Encontro precioso". As bonecas Abayomi eram produzidas a partir de retalhos das saias das mães africanas e, a partir deles criavam pequenas bonecas, feitas de tranças ou nós, que serviam como amuleto de proteção para acalentar seus filhos durante as terríveis viagens a bordo dos tumbeiros (navio de pequeno porte que realizava o transporte das pessoas escravizadas entre África e Brasil). 


\section{Helen Moura Pessoa}

Doutora em Educação, Professora Adjunta da Universidade Federal do Espírito Santo (UFES) - Campus Alegre, Alegre/ES; Pesquisadora do Núcleo Interdisciplinar de Pesquisa e Estudos em Educação Ambiental (Nipeea) - PPGE/UFES - Vitória/ES.

E-mail: helen.brandao@ufes.br

Contato:

Secretaria Unificada de Departamentos do CCENS (Departamento de Química e Física)

Alto Universitário, s/nº - Guararema

Alegre - ES | Brasil

CEP 29.500-000

Editor responsável:

Rosana Louro Ferreira Silva

Contato:

Centro de Ensino de Ciências e Matemática de Minas Gerais - CECIMIG

Faculdade de Educação - Universidade Federal de Minas Gerais

revistaepec@gmail.com 